general practitioners list her under the various organic "illnesses " proposed by her and accepled by the doctors. Is this sensible "medicine" or only a matier of convenience, a kind of short-term, and perhaps short-sighted, thinking? And how many cases diagnosed and listed in our statistics as organic, might turn out-if properly examined-to belong to this category?

All these aspects of the case were thoroughly thrashed out in a long discussion at our seminar. The following week we learnt from Dr. B. that when he saw the patient on the day after the seminar her depression seemed more tolerable-perhaps it was better, or maybe the doctor was bet:er. To cut a long story short, patient and doctor could talk to each other; a good deal more of her previous history was revealed which threw new light on the possible causes of the something "bad" collecting in her. In the end the emergency appointment with the psychiatrist for E.C.T. was cancelled, as neither patient nor doctor felt any urgent need of it. Let me add, drinamyl was neither prescribed nor asked for, but a psychotherapeutic relationship was started-it is true, somewhat late in the day, and so with only a very guarded though not absolutely bad prognosis.

The real change achieved at this point was that the doctor approached the patient in a different mood, in a different spirit ; instead of trying to find some not quite relevantor even irrelevant-organic change, he established a psychotherapeutic relationship with the patient, which may grow into something. Whether he himself will be able to continue the treatment or will have to refer the patient to a specialist is a matter of policy, not of principle. In other words, a tactical step, not a strategic decision. The strategic decision was taken when he sat down with his patient and listened to her. This kind of listening is an art, at least as difficult and subtle as using a stethoscope. Sill, training for this kind of listening is not yet included in the medical curriculum. Maybe it will be in the future.

As you see, here is a vast field of research accessible, above all, to the general practitioner. It is he who knows intimately the patient's previous history, and it is he to whom the patient first turns with his fears, pains, or worries -with all that medicine calls complaints, symptoms, or signs. It is the general practitioner-of all doctors-who can most easily get hold of and piece together the various bits of information about a patient, so that the picture should make sense. Moreover, his relationship with the patient is, as a rule, lasting, not ephemeral like that of a specialist. Thus he can conduct long-term observations extending over many years and can collect sufficient wellauthenticated material on the basis of which the short-term achievements of hospital medicine can be more accurately assessed. Obviously this cannot be done so long as general practitioners are overawed by the unquestionably great successes of hospital science and cannot consider their own observations valid and reliable.

\section{Help for the G.P.}

Here we-psychologically minded psychiatrists-can be of considerable help. It will be remembered that Dr. B., after the second interview, found Mrs. D.'s depression so severe that he arranged for an immediate E.C.T. I do not wish to raise here the much-discussed problem of shock therapy; for our case this is a side issue. What is important, however, is that Dr. B. could not bear the woman's depression; it was too much for him. The more our experiences in our seminars grow, the more we become impressed by the amount of therapy prescribed-sit venia verbo-to help the doctor. Whether this kind of prescription helps the patient is another matter. The chief assistance that we psychiatrists can offer a general practitioner is to enable him to become aware of his own involvement in his patients and so help him to respond better, more freely, and more accurately to their needs, while being less encumbered by his own emotions.
This is by no means an easy task, and I am rather doubtful how far an individual general practitioner can achieve it on his own. One promising method for acquiring this self-awareness and with it a modicum of psychotherapeutic skill is participation in our research-cum-training seminars. I know that one case is not sufficient proof for such a peremptory announcement, but it was impossible to quote more here.

\section{Conclusion}

So may I sum up : The most important aspect of the problem "general practitioner and psychotherapy" is to understand the presenting complaints as symptoms of the patient's whole life history. In order to achieve this the general practitioner must become less dependent on-that is, more critical of-hospital medicine and with it more confident about his own observations. Further, an equally important condition, he must become aware of his own involvement in his patients' problems in order to control his responses more accurately. Whether this latter can be achieved without outside help must remain for the time being undecided.

\section{PSYCHOTHERAPY AND THE GENERAL PRACTITIONER-II*}

BY

\section{P. R. SAVILLE, M.R.C.S., L.R.C.P.}

I shall deal with only a few of the aspects of psychiatry as related to general practice, and it would perhaps be of most interest if I concentrate mainly on the influence which the research seminars at the Tavistock Clinic had on my work as a general practitioner and give some general idea of the nature of our group and its atmosphere.

\section{Problems of the G.P.}

It soon became apparent that the problems of general practitioners were different from those of the psychiatrists, in so far as we have large numbers of patients who have to be dealt with on the spot, so to speak. We cannot pick and choose ; we cannot put them off; we cannot tell them to go elsewhere because we are too busy. They have to be dealt with there and then, and it becomes obvious that we must necessarily evolve different techniques to treat them. As, in the normal course of events, psychiatry in general practice does not exist at all, we had to work it out for ourselves over a period of a few years, and it is really the purpose of this contribution to demonstrate how valuable and rewarding was the time spent at the seminars, and how much it has helped me in my everyday work.

It must be remembered that we have originally been trained to think in terms of pathological processes and have in our minds a list of drugs which will alleviate these conditions. When I was a student it was a very small list, but it is much larger now ; in fact, the advent of the antibiotics has enabled us to really cure people of certain inflammatory diseases. But in my early training disease of the mind (other than frank lunacy) was relegated to the diagnosis of patients after full investigation had revealed no organic cause. At that stage we produced a medical sneer, our attitude changed to one of contempt, and we labelled the patient "a neurotic"- - a dreadful slur. We sometimes let the patient down more lightly by calling his condition " functional." We felt we had done a jolly good job at this stage

* Read in the Section of Psychiatry at the Annual Meeting of the British Medical Association, Brighton, 1956. 
-no germs were found, no growths, and so there was nothing really wrong with him; therefore he could get on with it himself.

Unfortunately, the patient showed great reluctance to get on with it himself, and continued to plague us with his complaints. At this stage we got rid of him-to the psychiatrist, who, queer chap though he was, became rather useful after all. What he did with the patient was none of our business, but he performed his main function adequately-by keeping the patient away from us.

We learned that he was a kind sort of chap who sat down for half an hour or more and actually listened to the patient!

This was indeed a revolutionary idea, and, more surprising, it occasionally seemed to do some good. This made some of the more enlightened of us sit up and take note and attempt to follow suit, but it soon became apparent that one had to know how to listen. It was not all that simple ; but how to acquire that valuable art was another matter-in fact, there was no practical way of doing it. The usual long and costly special training was out of the question for a busy general practitioner. One read a few books and attended the occasional lecture by a chap who seemed to have heard of Freud. But it did not really help.

\section{Research Seminar at the Tavistock Clinic}

At last the heaven-sent answer to our prayers arrived. The Tavistock Clinic attempted some solution to our problem, and, I think, succeeded very well.

A group of eight doctors met weekly to discuss our own cases, as a research seminar. We were a varied group, with only one thing in common-that we were all doctors in general practice. The sexes, ages, and nationalities were mixed. We had the usual tensions of any therapeutic group, for that is what we inevitably became (in a mild sort of way). We got to know each other really well and we recognized each other's patterns, idiosyncrasies, and weaknesses, and were fully conscious that everyone else was just as aware of our own deficiencies.

We gradually became more and more cognizant of the intricacies of the hackneyed doctor-patient relationship, and the traditional " bottle" was given a little extra meaning.

Listening to our colleagues relating their own cases (with some cunning and judicious guidance from the psychiatrist leader) it soon became apparent how varied and different we all were in our individual approaches to the patient, and how we all expected him to conform to certain patterns of behaviour, each of us taking it for granted that our own brand of expectation was the correct one.

Most of us learned to examine our own attitudes in the light of these discoveries, and our increasing ability to acknowledge and accept criticism was a very noticeable byproduct.

Incidentally, we became highly critical of each othernot much was missed by us, and indeed we were often brutal. This was where the psychiatrist was called upon to exercise all his skill in keeping the temperature at a reasonable level. We began to understand what he meant when he spoke about the "apostolic function" of the doctor-one of his pet hobby-horses.

We were also given the opportunity of discussing difficulties concerning our own cases with one of the psychiatrists at the Tavistock Clinic (other than the seminar leader).

All this helped to increase our elasticity, so necessary in dealing with patients in general practice, reducing tension, and, most important, removing some of our own guilt feelings towards patients. We also noted that the patient responded favourably to our new type of approach and our new style of listening. We got to know something about what could be done for different patients, who could benefit by psychotherapy, and who should not be referred to a psychiatrist.
We even attempted psychotherapy ourselves. At first we looked for startling and dramatic cases, and in fact got what appeared to be amazing results - so much so that it made some of us over-ambitious. But after a bit we learned that beginners' luck did not continue to hold, and with some miserable failures we gradually dropped attempts at major psychotherapy and became more aware of our own limitations and more sensitive to what we could and should attempt, finally settling down to a type of therapy varying with our own individual skill and inclination. In my own case a combination of ventilation, reassurance, and counselling.

My personal development in the group was one of wonder at what was attempted and achieved by certain other members of the group, and then came a remarkable result in one of my early cases, a bit of magic which rather overstimulated me.

I was soon disillusioned by a dismal failure, and finally settled to my present level of treatment. I think I can best illustrate this development by relating a few details of three cases.

\section{Case 1}

The patient was a thin, pale, inoffensive man aged 26 who had been married three weeks. He complained of splitting headaches (" behind his eyes"), so severe that he could not walk and had to be taken to hospital in a taxi, where he was admitted there and then and investigated for possible cerebral cause or acute sinusitis. He reported to me immediately he left hospital, complaining that his headaches were still severe.

I knew his family set-up well-his blind father (now dead), whom he used to lead about ; recent marriage ; wife's healed tuberculosis; childhood in orphanage - and something clicked. I dived right in, spent an hour with him, took a full history, and with plentiful material made an immediate interpretation, tracing it back to his childhood in the orphanage, associating himself with his blind father, to whom he was greatly attached-and perhaps unconsciously resented, with headaches (always behind eyes). He was assured of the non-organic origin of the headache. There was a good deal more interpretation involving his wife, a newly acquired motor-cycle, his relationship with an elder brother, and his Cinderella-like role in life.

The patient accepted the interpretation fully. I saw him a few days later. He said he felt marvellous, "no headaches," and now understood that his symptoms were related to his abnormal childhood. He was no longer afraid of crowds, slept well, and was most grateful to me. This all happened in March, 1953. I think you will agree that he was suffering from a severe anxiety neurosis.

Over three years have elapsed. $\mathrm{He}$ is the proud father of a bouncing baby girl, aged 1 ; loses no time from work, and rarely reports to me, except for tonsillitis and such-like complaints. His wife tells me how well he is. I feel you might bear with me if I allowed myself to be carried away by this case.

\section{Case 2}

I was soon brought back to earth by my next case. A young man of 22 , who could not report for his annual military training, was seized at the railway station with dizziness, apprehension, and near collapse. In a few sessions I was overwhelmed by a mass of homosexual material plus a rapidly developing positive transference. It was all there for the asking if one knew what to do with it. But I could not handle it ; I was overwhelmed hy the weight and content of the material presented to me, and I panicked-more or less ran away, or rather made the patient run away. He avoided me after that, with his problem unsolved. I I understood from his mother, who was quite pleased about her son now, that he had a boy friend living with him and that he had settled down and was quite happy. So I nearly spoiled that romance. 
This experience made me wary, and I developed more restraint and took on only the type of case I felt I could properly handle.

\section{Case 3}

My third patient was the sort of case I now feel I can do most for. She was a worried-looking married woman of 41 , who had consulted me regularly for six to eight years, practically weekly, complaining of a multitude of symptoms, including sweats, headaches, "fibrositis," pain in the chest, " pins and needles," with never any abnormal physical signs. She also had waves of depression and crying bouts. It was always obvious that her symptoms were psychogenic in origin, but $I$ had been disinclined to tackle them on that level, until the stimulating effect of the group influenced me to arrange an appointment with her, after surgery hours, so that I could really listen to her.

I spent an hour with her and listened. I heard about her drunken father, who used to beat her overworked mother, and about terrifying scenes with parents fighting and children in the street in the early hours of the morning; stitches put in mother's wounds; scenes at police courts; her mother's death followed by a stepmother in the house; and her own early marriage to get away from home.

Then came discussion of her own frigidity and memories of witnessing parental intercourse. I had to do little more than listen. The floodgates were opened, and for the first time in her life she spoke about those unmentionable things.

My interpretation was minimal, and I let her talk with only a little prompting here and there. This all happened in March, 1954, over two years ago. I see her only occasionally now, very much less than in the past. Her whole attitude is different and our relationship is especially good; we understand each other. We have friendly, encouraging chats, and we have both silently agreed not to go too deeply into it.

My heart no longer sinks as she walks into my consultingroom, and she no longer looks miserable when she walks in. In fact, the doctor has not only done the patient some good but the patient has also helped the doctor. She even brought me a new patient a few months ago.

I must emphasize that this case, so apparently simple in every way, would not have been possible for me in my pre-Tavistock Clinic days. I had learned to listen.

\section{ORDER OF ST. JOHN OF JERUSALEM}

The London Gazette has announced the following promotions in, and appointments to, the Venerable Order of the Hospital of St. John of Jerusalem :

As Knights: Surgeon Vice-Admiral Sir K. A. InglebyMackenzie, K.B.E., C.B., M.R.C.S., L.R.C.P., Q.H.P., Brigadier Sir A. E. Porritt, K.C.M.G., C.B.E., F.R.C.S., and Colonel G. D. English, M.B. As Commanders (Brothers): Surgeon Vice-Admiral R. C. May, C.B., O.B.E., M.C., M.R.C.S., L.R.C.P., Q.H.S., Major-General F.' K. Norris, C.B., C.B.E., D.S.O., M.D., Air Vice-Marshals P. B. L. Potter, C.B.E., M.D., Q.H.S., and E. A. Daley, C.B.E., M.B., Drs. R. Cauchi-Inglott, M.B.E., M.D., A. T. McKay, W. W. King-Brown, R. Chester, T. C. James, G. L. C. Colenso-Jones, A. J. Boase, O.B.E., and N. H. Ashton. As Officers (Brothers): Lieutenant-Colonels W. Windsor, M.R.C.S., L.R.C.P., and I. A. Walsh, M.B., R.A.M.C., Wing Commander W. O. Davies, M.R.C.S., L.R.C.P., Drs. W. E. Talbot, A. R. Shaw, Chang Hoey Chan, I. Mackenzie, A. K. MacRae, A. Kefaals, M. A. Watson, T.D., R. Brown, J. E. King, G. Walker, W. E. Lock, H. A Korn, D. J. Turnbull, G. Thompson, N. J. Caldwell, A. M. Purves, V. C. Dyring, L. N. Gollan, J. A. Waycott, and E. O. Halliwell. As Serving Brothers: Mr. W. A. L. Tucker, F.R.C.S., Drs. Mohammed Ahmed, I. McCracken, H. H. Coulter, F. D. Morphy, M C., J. T. Paranjothy, Kong Sau-Yui, W. Grima, J Saliba, E. Cesareo, E. H. B. Grey, A. Edwards, J M. Sherriff, R. S. Abraham, T. F. Greenwood, T. Cullen, W. B. Ballenden, W. Kirkwood, J. F. Coates, A. St. C. R. de Costa, M.B.E., D T. Gilbert, and F. E. Fletcher. As Associate Serving Brothers: Mr. I. B. Taylor, Drs. L. K. Luk, G. Frampton, and H. M. Wolfsohn. As Serving Sisters: Drs. Evelyn W. A. Churches, Stella C. C. Macdonald, and Catherine J. S. Sedgwick.

\section{Correspondence}

Because of heavy pressure on our space, correspondents are asked to keep their letters short.

\section{Smoking and Lung Cancer}

SIR,-It is refreshing to read Dr. E. L. Wynder's new approach (Journal, January 5, p. 1) towards the solution of the tobacco-cancer problem and to see that, instead of trying to stop us smoking, he is pursuing his researches with a view to letting us continue to smoke while ridding the cigarette of its carcinogenic properties.

I think that most doctors in this country not only accept now the association between cigarette smoking and cancer but, moreover, assume that tobacco smoking is carcinogenic. One should, however, utter a word of warning to those who compute mathematically the increased risk at which smokers are in respect of cancer of the lung. There are several definite, and probably a still greater number of hypothetical, factors which may be associated with smoking. It is clear, for example, that there is some relationship between smoking and the consumption of alcohol. In the group of lifelong non-smokers are a number of persons who abstain from smoking as a matter of personal or religious principle, and most of these abstain also from alcohol. At the other end of the scale. men who drink spirits in excess nearly all smoke cigarettes too. In the small group of people who relapse after having stopped smoking drinking men bulk very large. The first cigarette is very often smoked at a party. It is therefore clear that an association does exist between alcohol and tobacco, and consequently it would be inevitable that an investigation of alcohol consumption would show a relationship between alcohol and cancer of the lung, even if there is a carcinogen in tobacco smoke. The association between alcohol and cancer of the lung would, in fact, be a false association, and false associations are the bugbears of those who conduct statistical research. Nor should we too lightly dismiss the effect that alcohol unquestionably has on respiratory function.

No one would make the absurd mistake of ascribing cancer of the lung to alcohol, but in fact that such an obvious association has not yet been reported or discussed by the authors of papers on this subject shows clearly how great a risk there may be of some factor other than tobacco smoking having a bearing on the problem of cancer of the lung. Additional associations of this kind, concealed in mortality statistics, should make us very wary of accepting calculations of the risk of cancer of the lung to which smokers are exposed. Moreover, now that cancer of the throat and gullet is being examined for a possible relationship with tobacco, extreme care will be necessary to exclude a possible causal relationship with alcohol. Such a relationship might occasion a false association between tobacco and cancer of these parts of the body, for cancer of the throat and gullet is certainly commoner in alcoholic subjects.

We have planned an investigation of the relationship between drinking and smoking, and when. in due course, your readers are invited to complete a short questionary, perhaps they would be good enough to co-operate with us. -I am, etc.,

London, W.12.

IAN AIRD.

\section{Function of the Prostate}

SIR,-I have been most interested in the correspondence on the function of the prostate. Dr. J. A. L. Magee (Journal, December 15, 1956. p. 1427) feels convinced that the prostate is the functionless remains, in the male, of the uterus and vagina. Surely this cannot be so, because it appears that the prostate depends for its development on the presence of functioning male gonads. In the immature male the prostate is small and hardly palpable, 